\title{
Effect of anemia on clinical outcomes in patients with coronary artery disease treated with percutaneous coronary intervention
}

\author{
Wojciech Wańha', James Cornwall², Wojciech Wojakowski ${ }^{1}$ \\ ${ }^{1}$ Third Department of Cardiology, Medical University of Katowice, Poland \\ 2Mount Sinai School of Medicine, New York, USA
}

Postep Kardiol Inter 2012; 8, 4 (30): 293-296

DOI: $10.5114 /$ pwki.2012.31910

\begin{abstract}
Coexistence of coronary artery disease with anemia is associated with an increased risk of death, myocardial infarction and bleeding complications. Presence of anemia adversely affects the outcomes of percutaneous coronary intervention, in particular in acute coronary intervention (ACS). Incidence of anemia in patients with ACS is relatively high (approx. 19-30\%), so hemoglobin levels should be evaluated upon admission, and considered in risk stratification.
\end{abstract}

Key words: anemia, coronary artery disease, percutaneous coronary intervention

\section{Introduction}

In recent years, there has been significant progress in the treatment of coronary artery disease (CAD). Pharmacological developments and myocardial revascularization techniques have led to decreased mortality and improved quality of life. Despite significant progress in its treatment, CAD is still the most common cause of death in middleaged and elderly individuals. In addition to the well-known risk factors such as age, male gender, smoking, dyslipidemia, and impaired glucose tolerance, increasing importance is being attributed to the role of hematological disorders in CAD, such as low levels of hemoglobin $(\mathrm{Hb})$. According to World Health Organization (WHO), anemia is defined as $\mathrm{Hb}$ levels below $13 \mathrm{mg} / \mathrm{dl}$ in men and $12 \mathrm{mg} / \mathrm{dl}$ in women [1]. The combination of CAD and anemia is a common clinical problem that leads to increased mortality and higher incidence of major adverse cardiac and cerebrovascular events (MACCE). Anemia is one of the most common hematological abnormalities in patients with $C A D$, occurring in $19-30 \%$ of patients with acute coronary syndromes (ACS) [2]. Elderly patients with STEMI have particularly high incidence of anemia which is reported in $10.5 \%$ [3] of older patients with myocardial infarction (MI) and $10.5 \%$ to $12.8 \%$ [4] to $12.8 \%$ [5] of patients with ST-segment elevation myocardial infarction (STEMI).
Etiology and pathophysiology of anemia in patients with coronary artery disease

The most common causes of anemia in elderly individuals include the presence of chronic diseases (35\%), iron deficiency (15\%), blood loss (7\%), renal failure, liver disease and endocrine disease (6.5\%), myelodysplasia, leukemia (5.5\%), vitamin $\mathrm{B}_{12}$ and folic acid deficiency (5.5\%) [5]. Anemia in the course of chronic disease is associated with stimulation of the immune system, infection, and inflammation. The decrease in $\mathrm{Hb}$ leads to reduced oxygen delivery to the myocardium, especially in the presence of significant coronary stenoses [6]. Reduced oxygen delivery leads to compensatory sympathetic stimulation, which increases cardiac output by increasing stroke volume and heart rate. The increased cardiac output contributes to the development of myocardial remodeling and left ventricular hypertrophy.

\section{Characteristics of patients with anemia and acute coronary syndrome}

Common characteristics among the population of CAD patients with associated anemia include: female gender [2, 7], advanced age [2, 7-9], hypertension [8], diabetes $[7,8,10]$, heart failure (HF) $[2,7,11-13]$, tachycardia $[2,7]$, renal failure $[2,7,14]$, lower body mass index (BMI) $[7,11]$

\section{Corresponding author:}

Wojciech Wańha MD, Third Departament of Cardiology, Medical University of Katowice, 45/47 Ziołowa St, 40-635 Katowice-Ochojec, Poland, tel.: +48 504827 636, e-mail: wojtwanh@wp.pl

Praca wpłynęła: 26.07.2012, przyjęta do druku: 31.08.2012. 
and higher Killip-Kimball class in patient with AMI [11] These patients are less likely to smoke cigarettes [2,7] compared with patients with normal $\mathrm{Hb}$ levels. Furthermore, these patients frequently have multi-vessel coronary artery disease [8, 13], sudden cardiac arrest [13], indications for intra-aortic balloon pump (IABP) [14], and a history of CV events and revascularization (PCI, CABG) [8]. Less commonly, these patients have $\mathrm{MI}$ with ST segment elevation [15], and are less likely to undergo revascularization for MI during hospitalization [2].

\section{Outcomes among patients with coexisting anemia and coronary heart disease}

Coexisting anemia is associated with worse outcomes across the spectrum of ACS, HF, and stable CAD treated with primary percutaneous coronary intervention $(\mathrm{PCI})$ or bypass surgery (CABG) [1, 16-19]. Hemoglobin level on admission in patients with acute coronary syndrome (ACS) is an independent risk factor for adverse CV events such as death, MI, and bleeding complications $[4,7,8,17]$. Several studies indicate the adverse effects of anemia, but there was no clear evaluation of a $\mathrm{Hb}$ threshold value that leads to adverse CV events. Sabatine et al. [2] completed a meta-analysis of 16 clinical trials, which included a total of 39,922 patients. The goal was to assess the impact of anemia on the occurrence of MACE in 30-day observation in order to identify a threshold value of $\mathrm{Hb}$ that increases the risk of adverse outcomes in ACS. This study showed that the relation between the risk of CV events and $\mathrm{Hb}$ levels has a reverse J-shaped distribution. It is noteworthy that the value of $\mathrm{Hb}$ below which there was an observed increase in MACE differed for STEMI and non-STsegment elevation ACS (NSTE-ACS) in 30-day observation. In patients with STEMI, when $\mathrm{Hb}$ values of $14 \mathrm{~g} / \mathrm{dl}$ to $15 \mathrm{~g} / \mathrm{dl}$ were used as the reference, $\mathrm{Hb}$ levels below $14 \mathrm{~g} / \mathrm{dl}$ were associated with an increase in mortality from CV causes for each $1 \mathrm{~g} / \mathrm{dl}$ decrement in $\mathrm{Hb}$. In patients with NSTE-ACS, when $\mathrm{Hb}$ values of $15 \mathrm{~g} / \mathrm{dl}$ to $16 \mathrm{~g} / \mathrm{dl}$ were used as the reference, $\mathrm{Hb}$ levels below $11 \mathrm{~g} / \mathrm{dl}$ were associated with an increase in mortality from CV causes, $\mathrm{MI}$, or recurrent ischemia for each $1 \mathrm{~g} / \mathrm{dl}$ decrement in $\mathrm{Hb}$.

The difference in the $\mathrm{Hb}$ thresholds may be due to the pathophysiology of STEMI and NSTE-ACS. In STEMI, abrupt occlusion of coronary vessel reduces the chance of developing collateral circulation. In NSTE-ACS, ischemia may be caused by progressive restriction of blood flow, usually not leading to complete occlusion [2]. Wu et al. [20] also observed an increase in 30-day mortality among patients with coexisting anemia and ACS in a retrospective registry including 78,973 patients aged $\geq 65$ years, hospitalized for MI. Shock, HF, and death during hospitalization were reported more frequently in patients with low hematocrit (HCT). Furthermore, a blood transfusion at HCT $\leq 30 \%$ was associated with decreased 30 -day mortality. Another analysis compared the adverse effects of anemia in patients after PCI. The CADILLAC trial [4] enrolled 2,027 patients with $\mathrm{AMI}$ who had undergone $\mathrm{PCl}$. Anemia at admission was associated with higher mortality at hospitalization ( $4.6 \%$ vs. $1.1 \%, p=0.0003$ ), 30-day follow-up (5.8\% vs. $1.5 \%, p<0.0001)$ and 1 -year follow-up (9.4\% vs. $3.5 \%, p<0.0001$ ). Cavusoglu et al. [21] assessed the use of anemia as an independent predictor of outcomes in 192 male patients presenting with ACS. At 24 months, the event-free survival was $64 \%$ in the group with a hemoglobin level $<13 \mathrm{~g} / \mathrm{dl}$ compared with $81 \%$ in the group with a hemoglobin level $>13 \mathrm{~g} / \mathrm{dl}$. Furthermore, Lee et al. [8] analyzed data at two points in time, after 30 days and at 1 year post $\mathrm{PCl}$. In comparison to patients with normal $\mathrm{Hb}$ levels, patients with anemia reported higher incidences of MACE, higher levels of troponin I, higher levels of CK$\mathrm{MB}$, and longer hospitalization after $\mathrm{PCl}$. Patients were divided into three groups based on the baseline $\mathrm{Hb}$ level: $>12 \mathrm{~g} / \mathrm{dl}, 10-12 \mathrm{~g} / \mathrm{dl}$, < $10 \mathrm{~g} / \mathrm{dl}$.

The best 1-year survival was observed in patients with $\mathrm{Hb}>12 \mathrm{~g} / \mathrm{dl}$, and the worst with $\mathrm{Hb}<10 \mathrm{~g} / \mathrm{dl}$. Notably, another study reported less than a 3-year survival rate in men with $\mathrm{Hb} \leq 12.9 \mathrm{~g} / \mathrm{dl}$ prior to $\mathrm{PCl}$. Ronald et al. [13] analyzed the impact of anemia on the results of $\mathrm{PCl}$ during hospitalization in 48,851 patients. They concluded that patients with anemia were at higher risk of death, MI, and in-hospital MACCE. Outcomes of the study include gender differences, since death after $\mathrm{PCl}$ was more frequent in men and $\mathrm{Ml}$ after $\mathrm{PCl}$ was more common in women. Anemia was an independent factor influencing mortality in men. Mortality and hospitalization rates for patients admitted with $\mathrm{MI}$ complicated by HF and low $\mathrm{Hb}$ are notably higher over a 3 year follow up period according to the OPTIMAAL trial [9].

It was noted that it is important to evaluate not only anemia upon admission, but also anemia after discharge from hospital, which is also an independent factor affecting mortality. Prognostic value of anemia in patients with STEMI and left ventricular dysfunction was documented in the TRACE study [23], which involved 1,731 patients with LVEF $<35 \%$. Severe anemia concomitant with a decrease in LVEF was associated with higher mortality, particularly in patients with HF.

\section{Bleeding}

Bleeding is the most common non-cardiac complication in patients with ACS [8]. Anemia at admission is an independent predictor of bleeding, related and non-related to $\mathrm{PCl}$ in patients with ACS including STEMI and NSTE-ACS $[4,24]$. The OASIS 5 and 6 trials [7], which enrolled 32,170 patients with ACS, showed an inverse relation between $\mathrm{Hb}$ levels at admission and major bleeding risk among STEMI and NSTE-ACS patients. There was a gradual increase in the risk of bleeding and red blood cell transfusion, which was associated with an increased risk of CV events, as Hb level decreased. The ACUITY trial compared 
treatment with bivalirudin versus heparin plus glycoprotein IIb/IIla inhibitor in 13,919 patients with ACS [24]. The analysis showed 30-day mortality in patients with bleeding of $7.3 \%$ vs. $1.2 \%$ in patients without bleeding in bivalirudin to heparin, respectively. Major bleeding was associated with higher 30-day mortality, ischemia, and stent thrombosis compared to patients without major bleeding, and was an independent predictor of 30-day mortality. In the study by Nikolsky et al. [4], patients with anemia frequently developed in-hospital hemorrhagic complications (6.2\% vs. $2.4 \%, p<0.002)$, and had higher rates of blood product transfusions (13.1\% vs. 3.1\%, $p<0.0001)$. Choosing the best vascular approach during PCI can significantly reduce the risk of bleeding. A radial approach reduced the incidence of blood transfusion by half and lowered the 30-day and 1-year mortality [25]. The European Society of Cardiology (ESC) Guidelines on diagnosis and treatment of NSTE-ACS recommended a blood transfusion in case of compromised hemodynamic status or haematocrit to $\mathrm{HCT}<25 \%$ or $\mathrm{Hb}$ level $<7 \mathrm{~g} / \mathrm{dl}[26]$.

\section{Antiplatelet therapy and intervention}

Interventional treatment in ACS is rarely practiced in patients with low Hb levels [7]. When selecting strategies, physicians should pay particular attention to the need for dual anti-platelet therapy (DAPT) after PCI. However, despite the favorable results observed with the use of DAPT after $\mathrm{PCl}$, for the prevention of stent thrombosis, DAPT is unfortunately also associated with an increased risk of major and minor bleeding compared to single agent therapy [27]. Another important issue is selection of the appropriate stent during $\mathrm{PCl}$ in patients with anemia. The recent registry of Shishehbor et al. demonstrated that the use of drug-eluting stents is beneficial in term of MACE reduction in patients with mild-to-moderate anemia and reduced the mortality in comparison to bare metal stents regardless of the $\mathrm{Hb}$ levels [28].

\section{Conclusions}

The coexistence of CAD with anemia is associated with an increased risk of death, $\mathrm{Ml}$ and bleeding complications. Presence of anemia adversely affects the outcomes of $\mathrm{PCl}$, in particular in ACS. Incidence of anemia in patients with ACS is relatively high (approx. 15-20\%), so Hb levels should be evaluated upon admission, and considered in risk stratification.

\section{References}

1. Nutritional anaemias. Report of a WHO scientific group. World Health Organ Tech Rep Ser 1968; 405: 5-37.

2. Sabatine MS, Morrow DA, Giugliano RP, et al. Association of hemoglobin levels with clinical outcomes in acute coronary syndromes. Circulation 2005; 111: 2042-9.

3. Tsujita K, Nikolsky E, Lansky AJ, et al. Impact of anemia on clinical outcomes of patients with ST-segment elevation myocardial infarction in relation to gender and adjunctive antithrombotic therapy (from the HORIZONS-AMI trial). Am J Cardiol 2010; 105: 1385-94.

4. Nikolsky E, Aymong ED, Halkin A, et al. Impact of anemia in patients with acute myocardial infarction undergoing primary percutaneous coronary intervention: analysis from the Controlled Abciximab and Device Investigation to Lower Late Angioplasty Complications (CADILLAC) Trial. J Am Coll Cardiol 2004; 44: 547-53.

5. Balducci L, Ershler WB, Krantz S. Anemia in the elderly-clinical findings and impact on health. Crit Rev Oncol Hematol 2006; 58 : 156-65.

6. Most AS, Ruocco NA Jr, Gewirtz H. Effect of a reduction in blood viscosity on maximal myocardial oxygen delivery distal to a moderate coronary stenosis. Circulation 1986; 74: 1085-92.

7. Bassand JP, Afzal R, Eikelboom J, et al. Relationship between baseline haemoglobin and major bleeding complications in acute coronary syndromes. Eur Heart J 2010; 31: 50-8.

8. Lee PC, Kini AS, Ahsan C, et al. Anemia is an independent predictor of mortality after percutaneous coronary intervention. J Am Coll Cardiol 2004; 44: 541-6.

9. Anker SD, Voors A, Okonko D, et al. Prevalence, incidence, and prognostic value of anaemia in patients after an acute myocardial infarction: data from the OPTIMAAL trial. Eur Heart J 2009; 30: 1331-9.

10. Craig KJ, Williams JD, Riley SG, et al. Anemia and diabetes in the absence of nephropathy. Diabetes Care 2005; 28: 1118-23.

11. Androne AS, Katz SD, Lund L, et al. Hemodilution is common in patients with advanced heart failure. Circulation 2003; 107: 226-9.

12. McClellan WM, Flanders WD, Langston RD, et al. Anemia and renal insufficiency are independent risk factors for death among patients with congestive heart failure admitted to community hospitals: a population-based study. J Am Soc Nephrol 2002; 13: 1928-36.

13. McKechnie RS, Smith D, Montoye C, et al. Prognostic implication of anemia on in-hospital outcomes after percutaneous coronary intervention. Circulation 2004; 110: 271-7.

14. NKF-DOQI clinical practice guidelines for the treatment of anemia of chronic renal failure. National Kidney Foundation-Dialysis Outcomes Quality Initiative. Am J Kidney Dis 1997; 30 (4 Suppl 3): S192-240.

15. Aronson D, Suleiman M, Agmon Y, et al. Changes in haemoglobin levels during hospital course and long-term outcome after acute myocardial infarction. Eur Heart J 2007; 28: 1289-96.

16. Gitt AK, Bueno H, Danchin N, et al. The role of cardiac registries in evidence-based medicine. Eur Heart J 2010; 31: 525-9.

17. Eisenstaedt R, Penninx BW, Woodman RC. Anemia in the elderly: current understanding and emerging concepts. Blood Rev 2006; 20: 213-26.

18. Silverberg DS, Wexler D, laina A, et al. Anemia, chronic renal disease and congestive heart failure - the cardio renal anemia syndrome: the need for cooperation between cardiologists and nephrologists. Int Urol Nephrol 2006; 38: 295-310.

19. Gillespie TW. Effects of cancer-related anemia on clinical and quality-of-life outcomes. Clin J Oncol Nurs 2002; 6: 206-11.

20. Wu WC, Rathore SS, Wang Y, et al. Blood transfusion in elderly patients with acute myocardial infarction. N Engl J Med 2001; 345 : 1230-6.

21. Cavusoglu E, Chopra V, Gupta A, et al. Usefulness of anemia in men as an independent predictor of two-year cardiovascular 
outcome in patients presenting with acute coronary syndrome. Am J Cardiol 2006; 98: 580-4.

22. Reinecke H, Trey T, Wellmann J, et al. Haemoglobin-related mortality in patients undergoing percutaneous coronary interventions. Eur Heart J 2003; 24: 2142-50.

23. Valeur N, Nielsen OW, McMurray JJ, et al. Anaemia is an independent predictor of mortality in patients with left ventricular systolic dysfunction following acute myocardial infarction. Eur J Heart Fail 2006; 8: 577-84.

24. Manoukian SV, Feit F, Mehran R, et al. Impact of major bleeding on 30-day mortality and clinical outcomes in patients with acute coronary syndromes: an analysis from the ACUITY Trial. J Am Coll Cardiol 2007; 49: 1362-8.

25. Chase AJ, Fretz EB, Warburton WP, et al. Association of the arterial access site at angioplasty with transfusion and mortality: the M.O.R.T.A.L study (Mortality benefit Of Reduced Transfusion after percutaneous coronary intervention via the Arm or Leg). Heart 2008; 94: 1019-25.

26. Hamm CW, Bassand JP, Agewall S, et al. ESC guidelines for the management of acute coronary syndromes in patients presenting without persistent ST-segment elevation. The Task Force for the management of acute coronary syndromes (ACS) in patients presenting without persistent ST-segment elevation of the European Society of Cardiology (ESC). Giornale Italiano di Cardiologia 2012; 13: 171-228.

27. Serebruany VL, Malinin AI, Ferguson JJ, et al. Bleeding risks of combination vs. single antiplatelet therapy: a meta-analysis of 18 randomized trials comprising 129,314 patients. Fundam Clin Pharmacol 2008; 22: 315-21.

28. Shishehbor MH, Filby SJ, Chhatriwalla AK, et al. Impact of drugeluting versus bare-metal stents on mortality in patients with anemia. JACC Cardiovasc Interv 2009; 2: 329-36. 